
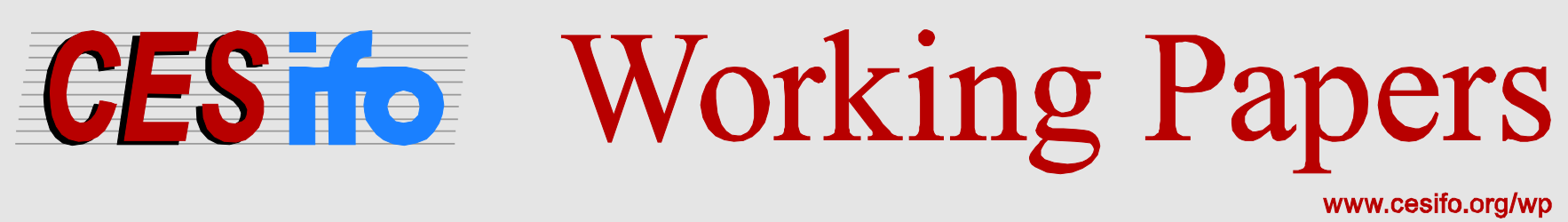

\title{
Cross-Border Tax Evasion under a Unilateral FATCA Regime
}

Dhammika Dharmapala

\author{
CESIFO WORKING PAPER NO. 5863 \\ CATEGORY 1: PUBLIC FinANCE \\ APRIL 2016
}
An electronic version of the paper may be downloaded
- from the SSRN website: Www.SSRN.com
- from the RePEc website: Www.RePEc.org
- from the CESifo website: www.CESifo-group.org/wp




\title{
Cross-Border Tax Evasion under a Unilateral FATCA Regime
}

\begin{abstract}
Cross-border tax evasion has emerged in recent years as a central issue in tax enforcement. Traditionally, the legal regime governing cross-border tax enforcement was based on information exchange upon request. In 2010, the US Congress enacted the Foreign Account Tax Compliance Act (FATCA), which seeks to induce foreign financial institutions (FFIs) to participate in a global regime of automatic information reporting of the income of US residents to the US government. This paper presents a simple theoretical model of cross-border investment that analyzes the consequences of this (unilateral) FATCA regime. The model emphasizes cross-border investors' (heterogeneous) intrinsic motivation to comply with tax law, as well as the impact of information reporting requirements on the cost of providing financial services. In FATCA-compliant equilibria (in which FFIs report information to the US government) FFIs face a higher cost of providing financial services, increasing the fees charged to their accountholders. Consequently, tax-compliant behavior - such as investing via their domestic financial sector - becomes more costly for foreign residents. Under certain conditions, a unilateral FATCA regime causes increased cross-border tax evasion among residents of foreign countries. This result is robust to various extensions.
\end{abstract}

JEL-Codes: H260.

Keywords: tax evasion, international taxation, FATCA.

\author{
Dhammika Dharmapala \\ University of Chicago Law School \\ USA - 60637 Chicago IL \\ dharmap@uchicago.edu
}

Revised version - March 2016

I thank the editor (Sören Blomquist), two anonymous referees, and participants at the Lisbon International and European Tax Law Seminar for comments on an earlier version of this paper, Mihir Desai and Itai Grinberg for helpful conversations, and Lauren Faraino for valuable discussions regarding the background to the FATCA regime. I also acknowledge the financial support of the Lee and Brena Freeman Faculty Research Fund at the University of Chicago Law School. Any remaining errors or omissions are my own. 


\section{1) Introduction}

Cross-border tax evasion has emerged in recent years as a central issue in international taxation and tax enforcement. Traditionally, the legal regime governing the enforcement of crossborder investors' tax obligations has been based on information exchange upon request. Tax treaties and Tax Information Exchange Agreements (TIEAs) provide for the exchange of information among governments under certain circumstances when one of the governmental parties requests information about the income of one of its residents. It is difficult to evaluate the success of this traditional regime, given the inherent difficulties of measuring tax evasion activity. However, it is widely believed that this regime allows individuals investing through financial institutions based abroad (especially, but not necessarily, in tax haven jurisdictions) to evade taxes owed to their country of residence with only a low probability of detection (e.g. Zucman, 2014).

In 2010, the US Congress enacted the Foreign Account Tax Compliance Act (FATCA) as part of a wider measure known as the Hiring Incentives to Restore Employment (HIRE) Act. The major aim of the FATCA approach is to induce foreign (i.e. non-US) financial institutions (FFIs) to participate in a global regime of automatic information reporting of the income of US residents to the US government. In order to induce FFIs to participate, the FATCA regime threatens to impose a substantial withholding tax on US-source payments to nonparticipating FFIs. Participation in this system entails significant compliance burdens for FFIs (of determining whether the beneficial owner of each account is a US tax resident and of automatic information reporting to the US). ${ }^{1}$ As originally envisaged, FATCA is a unilateral system in which automatic information reporting is used to enforce US tax law with respect to US residents' foreign accounts; foreign governments do not receive information on their residents' US (or other offshore) accounts. The FATCA framework has undergone various modifications since its enactment and its implementation has been repeatedly delayed; however, it began operating in 2015.

This paper presents a simple theoretical model that analyzes the consequences of a unilateral FATCA regime for tax compliance and tax revenues. In relation to the previous literature on tax evasion, it emphasizes two elements that have not been the focus of primary attention cross-border investors' (heterogeneous) intrinsic motivation to comply with residence country tax law, and the impact of information reporting requirements on the cost of providing financial

\footnotetext{
${ }^{1}$ See e.g. Kate Burgess “US legislation: Industry concerned at extraterritorial tax clampdown plan” Financial Times, May 8, 2012 (reporting on predictions of billions of dollars of compliance costs for non-US financial institutions).
} 
services. The baseline model assumes two countries - the US and a foreign country (F), each with a competitive financial sector. Individuals are assumed to be identical apart from an idiosyncratic utility cost of tax evasion. All financial institutions invest in the same diversified global portfolio of assets, and are assumed to differ only in their information reporting obligations. US residents can invest via a US financial institution (USFI) or via an FFI. In the former case, tax compliance is automatically induced by domestic information reporting requirements. In the latter case, investors can choose to evade US taxes and thereby incur their idiosyncratic utility cost of evasion, or can comply with US tax law by reporting their income to the US (thereby incurring a fixed "translation cost” of interpreting their FFI income in terms of US tax law). The paper characterizes the equilibrium outcomes in this pre-FATCA regime, in which the fraction of residents evading taxes in each country depends on the distribution of the idiosyncratic evasion cost among that country's population.

The paper then introduces a unilateral FATCA regime. We focus on FATCA-compliant equilibria in which FFIs participate in this regime, as these are most relevant for the analysis. FFIs now face an increased cost of providing financial services, as they must determine whether their accountholders are US residents and must establish an infrastructure for automatic reporting to the US (whether or not any accounts are held by US residents in equilibrium). Thus, they must comply simultaneously with the information reporting requirements of their home government and those of the US. Assuming a competitive financial sector, this raises the fees charged by FFIs to accountholders. Consequently, tax-compliant behavior - such as investing via the domestic financial sector - becomes more costly for F residents. In contrast, USFIs continue to face only one set of information reporting requirements - that of the US - and so their costs are unchanged by the unilateral FATCA system. For F residents, the cost of evading via USFIs is unchanged, while the cost of tax-compliant behavior increases. This leads to a larger fraction of $F$ residents engaging in cross-border evasion in equilibrium.

Thus, under certain conditions a unilateral FATCA regime causes increased cross-border tax evasion among residents of foreign countries. This result is robust to assuming that $F$ residents face an (asymmetric) fixed cost of investing via USFIs, due for instance to non-FATCA-related US regulations (unless this cost is prohibitively high, in which case there is no evasion via USFIs under the pre-FATCA regime as well). If the financial sector is assumed to be imperfectly competitive, the impact on evasion is mitigated. However, the welfare of country F is lowered as 
a result of FATCA by the decline in the economic profits earned by FFIs. The result is robust to a more general formulation of the cost of evasion, in which this cost is an increasing function of the amount of home country tax evaded. A further extension to the model adds a tax haven jurisdiction. This expands the set of choices available to US and F residents, but the central intuition described above remains basically operative here as well.

Since 2012, the US has significantly changed the original structure of the FATCA regime by signing Inter-Governmental Agreements (IGAs) to overcome legal obstacles to the implementation of FATCA (such as privacy laws in non-US jurisdictions that would be violated by FFIs reporting information to the US). Some (but by no means all) IGAs are formally reciprocal, allowing for USFIs to report information on non-US accountholders to their home governments. In principle, reciprocity would prevent any increase in evasion among F residents. Indeed, some commentators (e.g. Blank and Mason, 2014) see in this development the potential for the development of a multilateral version of FATCA, with global automatic reporting by all financial institutions to all of the world's governments. However, as discussed in more detail in Section 4.3 below, the compliance costs of such a regime (relative to the pre-FATCA equilibrium) should be taken into account, along with the benefits in terms of increased compliance and tax revenue. This paper highlights the increased costs of financial intermediation that would be entailed by such a regime - in particular, financial institutions would potentially need to report to over 200 different governments and to keep track of the tax laws of each of these countries.

This paper proceeds as follows. Section 2 briefly reviews the relevant literature. Section 3 describes the background to the FATCA system and highlights the main features that are most relevant for the paper's analysis. In Section 4, the model is developed and solved and its implications are discussed. Section 5 concludes.

\section{2) Literature Review}

This paper is related to several strands of literature, including those on the taxation of crossborder portfolio investment and on tax evasion. The voluminous literature on the economic modeling of tax evasion can be traced back to the pioneering contributions of Allingham and Sandmo (1972) and Srinivasan (1973). A particularly relevant strand of this work is on information exchange among governments in the setting of cross-border investment and evasion. Bacchetta and Espinosa (1995) analyze information exchange as a strategic choice made by governments. 
Keen and Ligthart (2006) provide an overview that emphasizes the centrality of information exchange in the design of contemporary international tax policy and tax enforcement. In our model, information exchange is not treated as a strategic choice, in order to focus instead on the impact of an exogenously-imposed FATCA regime of information reporting on the behavior of taxpayers.

The most closely related prior paper is Gérard and Granelli (2013). They develop a unified theoretical framework within which to analyze and compare the European Union (EU) Savings Directive and the FATCA regime, with a particular emphasis on the relative merits of information exchange and withholding taxes as mechanisms to combat cross-border evasion. They characterize a number of tax designs that achieve efficiency, which in their setting is one of perfect residencebased taxation. Our model has some similarities to theirs, in particular by assuming highly simplified portfolio choices. However, we do not analyze withholding taxes as an alternative to FATCA-style information exchange, nor do we focus, as Gérard and Granelli (2013) do, on the strategic choice of tax rates by revenue-maximizing governments. Instead, our focus is on how the FATCA regime affects the costs of providing financial services, and on how this regime affects the interaction between pecuniary incentives for evasion and intrinsic motivations for compliance with tax law.

There is also a literature on the taxation of cross-border portfolio investment that is of relevance. For example, Desai and Dharmapala (2011) develop a simple after-tax Capital Asset Pricing Model (CAPM) framework to model investors' cross-border portfolio choices. However, they do not directly model evasion. Their empirical results - using a change in the US tax on foreign-source dividend income from some (but not all) foreign countries as a source of identification - suggest that US portfolio investors are sensitive to US taxes on foreign dividend income. This might not be expected if evasion of US taxes on foreign dividends is commonplace. To be sure, there may also be substantial investment by evaders via FFIs that is not captured in this data. However, the result suggests that significant flows also exist via USFIs (or in other taxcompliant forms), even though the probability of detection of evasion via FFIs is presumably quite low.

It has long been noted that observed levels of tax compliance are difficult to explain using rational choice models in which individuals have purely pecuniary motivations (e.g. Andreoni, Erard and Feinstein, 1998). A recent literature argues that much of this compliance behavior is attributable to third-party information reporting (Kleven et al., 2011). In addition, a growing 
literature has emphasized the importance of intrinsic motivation (or "tax morale”) in explaining tax compliance (e.g. Luttmer and Singhal, 2014; Dwenger et al., 2015). In relation to the prior literature on cross-border evasion, the model in this paper places significantly more emphasis on intrinsic motivation to comply with tax law. This motivation is used to explain heterogeneity in compliance behavior among taxpayers who face identical pecuniary incentives for tax evasion.

\section{3) The FATCA Regime}

The pre-FATCA legal regime governing the enforcement of cross-border investors' tax obligations was based on information exchange upon request. Tax treaties and Tax Information Exchange Agreements (TIEAs) provided for the exchange of information among governments under certain circumstances when one of the governmental parties requested information about the income of one of its residents. Johannesen (2012) interprets the existing empirical evidence as suggesting that this regime of information exchange upon request creates only a modest probability of detection of cross-border tax evasion. ${ }^{2}$ Nonetheless, it is possible that intrinsic motivation to comply with tax law may nonetheless have generated a substantial degree of compliance even with a low probability of detection. This is suggested, for instance, by the findings of Desai and Dharmapala (2011) regarding the responsiveness of US portfolio investment to changes in the US taxation of foreign dividend income.

There has been growing concern over the past twenty years or so in the US about crossborder evasion, focused on both the loss of revenue and on perceptions of fairness. Prompted by these concerns, the US initiated the Qualified Intermediary (QI) system in 2001 (Harvey, 2012; Morse, 2012). While modest in relation to the subsequent FATCA regime, the QI system represented a significant departure from the traditional regime by creating direct reporting linkages between FFIs and the US government. The essential role of the QI system was to ensure that USsource income paid to accounts within FFIs were subject to the correct rate of withholding tax. FFIs could choose to become QIs of the Internal Revenue Service (IRS), providing information on the US-source income of US accountholders. In exchange, FFIs could maintain the confidentiality of their non-US accountholders, aggregating them by country to determine the correct withholding

\footnotetext{
${ }^{2}$ The bank secrecy laws of tax haven jurisdictions would arguably lower even further the probability of detection, although these laws have increasingly been eroded by the spread of TIEAs among havens. For general background and analysis of the role of tax havens, see e.g. Dharmapala (2008) and Dharmapala and Hines (2009).
} 
tax rate. However, the QI system did not apply to the foreign-source income of US residents, and allowed corporations to be treated as beneficial owners of accounts. Thus, US residents could establish foreign entities that they owned and controlled, but that could be treated as foreign beneficial owners of the account at the FFI. Moreover, relatively few FFIs chose to become QIs, enabling US evaders to invest via non-QI foreign vehicles (in which case the probability of detection was similar to that which prevailed prior to the QI system).

The FATCA regime enacted in 2010 sought to address these perceived shortcomings (Harvey, 2012; Morse, 2012; Grinberg, 2012). Proposals for this system were developed and legislation passed in a political climate shaped by scandals involving evasion-related US accounts at a Liechtenstein bank (LGT) and at the Swiss bank UBS. The new regime that emerged proved to be far-reaching and unprecedented in its ambition. The main feature of the FATCA regime is that it seeks to force all FFIs into a direct reporting relationship with the US government. Specifically, it requires participating FFIs to determine if each of their accountholders is or is not a US person (looking through shell entities to determine the ultimate beneficial owner, where applicable). Accountholders who fail to respond to inquiries of this nature and do not provide this information are to be deemed "recalcitrant" and have their accounts closed. Having determined the country of tax residence of their accountholders, participating FFIs are required to report automatically to the IRS the income earned by the accounts of US accountholders. From one perspective, this system can be viewed as an extension to the foreign arena of mechanisms of thirdparty reporting that have been highly successful in the domestic context in ensuring tax compliance. On the other hand, the FATCA regime represents a dramatic transformation of the international tax enforcement landscape, involving an unprecedented extension of US authority over FFIs that bypasses foreign governments.

The threat that is intended to induce cooperation by FFIs is a withholding tax at a $30 \%$ rate imposed on all payments by US entities (such as dividend payments by US corporations) to the FFI and its accountholders. Moreover, this tax would be imposed not only on dividends and interest, but also on gains from the sale of assets, on a gross proceeds basis (Dizdarevic, 2011). ${ }^{3}$ The applicable tax treaty withholding tax rate would in many cases be less than $30 \%$ (and would not be on a gross proceeds basis). To formally comply with treaty obligations, there is a process

\footnotetext{
${ }^{3}$ For instance, suppose that an accountholder of a nonparticipating FFI were to sell a US asset (with basis of \$80) for $\$ 100$. FATCA would impose a 30\% tax on the gross proceeds of the sale - i.e. a tax of \$30 on the gain of \$20.
} 
by which foreign taxpayers can seek a refund of the withholding tax to the extent that it exceeds the withholding tax specified in the tax treaty between the US and the taxpayer's country of residence. However, this system is widely thought to be highly cumbersome (Dizdarevic, 2011). ${ }^{4}$

In summary, the withholding tax would impose substantial burdens on a nonparticipating FFI and on its accountholders. Commentators argue that it is designed not as a tax but rather as a penalty to induce participation in FATCA regime (Dizdarevic, 2011). Clearly, the power of this threat is based on the prominent role of the US in the global economy - for instance, the US stock market accounts for approximately one third of the world's aggregate global stock market capitalization (and an even larger share of the free float that is available for purchase by portfolio investors). An FFI cannot offer accountholders (of any nationality) the opportunity to hold a diversified global portfolio of assets unless it invests in US assets. Thus, it is very costly for FFIs to avoid holding US assets in order to avoid the compliance burdens associated with FATCA. Equally clear is that this type of threat is available only to the US - if a small country ("Ruritania") were to attempt to implement a unilateral FATCA-type system, non-Ruritanian FIs would simply avoid holding Ruritanian assets, suffering little detriment as a consequence. In contrast, the threat of the US withholding tax would be expected to induce widespread participation in the FATCA regime among FFIs.

The FATCA legislation was enacted in 2010 and was originally expected to become operative from 2013. However, it soon became clear that there were significant legal and practical obstacles to its implementation in its original form. Particularly important were domestic laws in non-US jurisdictions protecting the privacy of accountholders' data, where the information reporting envisaged under FATCA would violate FFIs' domestic legal obligations. To overcome this problem, the US has fundamentally changed the structure of the emerging FATCA regime. Beginning in 2012, the US has signed a large number of intergovernmental agreements (IGAs) with other jurisdictions, designed to smooth the way for the implementation of a modified FATCA regime. $^{5}$

\footnotetext{
${ }^{4}$ In principle, the withholding tax may be creditable in a foreign accountholder's home country. However, the FATCA withholding tax may exceed the home country tax (especially as it is imposed on a gross proceeds basis). Possibly, it may also be creditable in many jurisdictions only to the extent of the treaty withholding tax rate, so that for the remainder, a taxpayer must resort to the cumbersome process for seeking a refund from the US.

${ }^{5}$ The list of 112 jurisdictions with which the US has signed IGAs is available at: https://www.treasury.gov/resource-center/tax-policy/treaties/Pages/FATCA.aspx
} 
There are three distinct models of IGAs that have emerged since 2012. The first two types both involve FFIs reporting information on accountholders (including US accountholders, if any) to their own governments. In turn, the foreign government (the "partner country”) reports US accountholders' income to the US government. This avoids the violation of privacy laws that would occur if the FFIs reported to the US directly. There are two forms of this type of IGA. One is unilateral - i.e. the partner jurisdiction undertakes to report information but without any reciprocal obligation for the US to report information on the partner country's residents' accounts in the US. The other is reciprocal, in that the US also undertakes to report information on residents of the partner country. The third model of an IGA involves the US and the partner country signing an agreement in which the latter agrees to a waiver of conflicting domestic laws, enabling FFIs to report directly to the US government. These types of agreements are nonreciprocal in structure.

At least in principle, reciprocal IGAs impose significant obligations on USFIs to report information to non-US governments. However, the status of IGAs as a matter of US law has been the subject of debate among legal scholars. ${ }^{6}$ Moreover, the reciprocal model IGA entails only a general acknowledgment by the US of the principle of reciprocity and a hope that future regulations and legislation will implement this principle. Thus, both legal scholars (e.g. Christians, 2013) and political scientists (e.g. Eccleston and Gray, 2014) have expressed skepticism about the extent to which even the nominally reciprocal IGAs will turn out to be reciprocal in practice, especially given the legal, political and administrative barriers to imposing significant costs on USFIs in pursuit of revenue for foreign governments.

\section{4) The Model}

\section{1) A Simple Two-Country Baseline Model}

\subsection{1) The Pre-FATCA Regime}

In our baseline model, we assume two countries - the US and a foreign country (F), which are assumed to be symmetric in most respects (except as specified below). Each country is populated by a continuum of individuals, with the total population size in each country normalized to 1 . Each individual within each country has an identical exogenously fixed wealth endowment

\footnotetext{
${ }^{6}$ This is because IGAs are neither treaties (as defined by the US Constitution), nor explicitly authorized by Congress - see e.g. Alison Christians “The Dubious Legal Pedigree of IGAs (and Why it Matters)" Tax Notes International, Vol. 69, No. 6, February 11, 2013, pp. 565-568 and Susan Morse "Why FATCA Intergovermental Agreements Bind the US Government” Tax Notes International, Vol. 70, No. 3, April 15, 2013, pp. 245-247.
} 
$W$. Within each country, individuals are identical in every respect, apart from an idiosyncratic cost of tax evasion that varies across individuals. This cost is denoted by $c_{i} \epsilon[0, \bar{c}]$, where $i$ indexes individuals. This can be interpreted as a utility cost that arises because individuals have internalized norms of tax compliance to varying degrees. In the basic analysis, $c_{i}$ is assumed to be a fixed cost for a given individual, and does not depend on the amount of tax evaded. However, in equilibrium individuals will either evade tax on all of their cross-border income or comply fully, so this assumption is not particularly crucial. Section 4.1 .5 below analyzes a more general formulation of the cost of evasion, where it is increasing in the amount of tax evaded. Among US residents, $c_{i}$ is distributed with pdf $f_{U S}\left(c_{i}\right)$ and cdf $F_{U S}\left(c_{i}\right)$. Among $\mathrm{F}$ residents, $c_{i}$ is distributed with pdf $f_{F}\left(c_{i}\right)$ and cdf $F_{F}\left(c_{i}\right)$.

Each country imposes a proportional tax on income generated by residents' investment of their wealth (on a residence basis on resident individuals' worldwide income). We assume that each country's tax rate is fixed and identical - i.e. that $t_{U S}=t_{F}=t$, where $t$ is the (common) tax rate. It is also assumed that individuals' country of residence is fixed, so the assumption that the tax rates are identical is an innocuous simplification. We assume that the countries do not impose withholding taxes at source. Withholding taxes would make evasion less attractive in general. However, the basic results (comparing the pre-FATCA and FATCA-compliant outcomes) would not be fundamentally changed, as long as withholding tax rates are lower than $t$.

There is assumed to be a competitive financial sector in each country. We refer to financial institutions (FIs) located in the US as USFIs and those located in country F as FFIs. While the country of domicile of each FI is fixed, we assume that FIs can manage the wealth of both domestic and foreign residents - i.e. a US resident individual can invest her wealth by opening an account with an FFI, and vice versa. In the baseline model, cross-border accounts are subject to the same costs as domestic accounts, although we consider scenarios in which there are (potentially asymmetric) additional costs of opening cross-border accounts. Each financial institution (wherever domiciled) is assumed to invest the funds it manages in a fully diversified global portfolio of assets with fixed return $r$. As the wealth endowment $W$ that an individual invests is fixed, the most natural interpretation of the return $r$ is as a dollar amount of income (rather than as a rate of return); similarly, $c_{i}$ and the fees and translation costs described below can also be interpreted as fixed amounts in dollar (or equivalent foreign currency) terms. 
We assume that individuals are unable manage their wealth themselves, and must do so via an FI. Whether an individual invests her wealth endowment through a USFI or a FFI does not affect her underlying asset portfolio or her pretax return, although - importantly - it affects the reporting of her income by the FI to the tax authorities. In the baseline setting, USFIs are required to report information on their accountholders to the US government, while FFIs are required to report information on their accountholders to the F government. Information exchange between the governments may be possible upon request, but is not automatic. It is assumed that the sanctions for violating these reporting requirements are sufficiently large that all FIs comply.

Direct costs of managing accountholders' wealth are normalized to zero, but reporting requirements entail positive administrative and compliance costs for FIs. The zero-profit equilibrium condition for a competitive financial sector entails that the fee charged by an FI to an accountholder is equal to the cost of complying with applicable tax reporting requirements. This cost is denoted by $\varphi>0$, which can be interpreted as a dollar amount independent of the amount invested, and is assumed to be the same for USFIs and FFIs (a largely innocuous simplification). While $\varphi$ is a fixed cost from the perspective of the accountholder, it may reflect either variable or fixed costs from the FI's standpoint. The simplest assumption is that $\varphi$ is a variable cost for the FI - the additional tax reporting cost due to an additional accountholder. However, in practice, there is likely to be a large fixed cost component of information reporting - for instance, the costs of learning tax law and setting up a reporting infrastructure - that is independent of the number of accountholders. The results are broadly similar if we view $\varphi$ as the component of those fixed costs that are allocated by the FI to each accountholder. The FIs' fees are assumed to not be taxdeductible; Section 4.1.4 below relaxes this assumption. We assume that FIs' fees are sufficiently small that $(1-t) r>\varphi$, and that $\bar{c}>t r$.

Consider the investment choices open to a US resident. If she invests her wealth via a USFI, her income will be automatically reported to the US government. If she attempts to evade, the probability of detection is 1 , and so it is reasonable to assume that even a small sanction will completely deter evasion. Thus, we assume henceforth that for a US resident, evading through a USFI is not a meaningful option. Her payoff from investing through a USFI is $(1-t) r-\varphi$. Alternatively, the US resident can invest her wealth via an FFI, which (under the pre-FATCA regime) will not automatically report her income to the US government. Investing via an FFI potentially entails exchange rate risk. In the basic analysis, we assume that the individual can 
purchase an exchange rate futures contract that perfectly hedges exchange rate risk for a (small) fixed $\operatorname{cost} \varepsilon ;{ }^{7}$ this is assumed to be sufficiently small that it is optimal for the individual to perfectly hedge the risk. If the cost is large, then there may be an interior solution in which the individual invests only part of her wealth through the FFI; this scenario is analyzed in Section 4.1.5 below.

Conditional on investing via an FFI, the US resident can either choose to evade or to comply with US taxation. In the former case, her probability of detection is relatively low, but she will in addition suffer the utility costs of tax evasion assumed above. Thus, her payoff is $r-\varphi-\varepsilon$ - $c_{i}$. If she invests via an FFI and reports her income to the US government, we assume that she incurs a compliance cost $\gamma>0$ that can be viewed as a "translation cost" from the tax law of $\mathrm{F}$ to that of the US. That is, the FFI will report to the US individual her income as defined by country F's tax law. In order to report this income to the US government, she must verify that this amount is also her income under US tax law. This verification requires an expenditure of resources (possibly to engage the services of tax professionals in both countries). ${ }^{8}$ We assume that $\gamma$ is a fixed cost, in the sense of being a fixed dollar amount (for instance, the fees charged by tax professionals) that is independent of the amount invested via the FFI and independent of the amount of taxable income. It is assumed that $\gamma$ is not tax-deductible, and that it is identical for US residents investing via an FFI and for F residents investing via a USFI (although both assumptions can be relaxed without fundamentally affecting the central results). Thus, if the US residents chooses to comply, her payoff is $(1-t) r-\varphi-\varepsilon-\gamma .{ }^{9}$

Under the assumptions above, investing via an FFI and complying with US tax law is a strictly dominated strategy because of the translation $\cos \gamma$ and the cost $\varepsilon$ of hedging exchange rate risk. Thus, a US resident's (undominated) choices are to evade via an FFI or to comply via a USFI. She will evade iff: ${ }^{10}$

i.e.

$$
\begin{gathered}
r-\varphi-\varepsilon-c_{i}>(1-t) r-\varphi \\
c_{i}<t r-\varepsilon
\end{gathered}
$$

\footnotetext{
${ }^{7}$ Note that the FFI is likely to be the efficient bearer of exchange rate risk, and may reasonably be assumed to bundle the futures contract with the other financial services it offers.

${ }^{8}$ Note that $\gamma$ is not incurred when the US individual invests via a USFI, as the USFI will report her income as defined by US tax law.

${ }^{9}$ For instance, suppose that the US resident invests $\$ 100$ in the FFI and earns $\$ 10$, with a translation cost of $\$ 1$. If she complies and the tax rate is $20 \%$, then (ignoring the FFI's fee and the cost of hedging exchange rate risk), her payoff $=(0.8) 10-1=\$ 7$. If her income were instead $\$ 15, \gamma, \varphi$, and $\varepsilon$ would be unchanged and her payoff would be (0.8)15 $-1=\$ 11$.

${ }^{10}$ Note that we make the tiebreaking assumption that an individual who is indifferent will invest via a USFI and comply.
} 
We denote by $c_{P}^{U S}$ this critical threshold value of evasion costs below which US individuals evade in the pre-FATCA regime. Thus, a fraction $F_{U S}(t r-\varepsilon)$ of US residents will engage in crossborder tax evasion. As $F_{U S}$ is nondecreasing, a larger fraction of individuals will evade the higher is the tax rate and the higher is the pretax return, and the lower is the cost of insuring against exchange rate risk. As long as $\bar{c}>t r-\varepsilon$, however, some individuals will not evade, despite the pecuniary incentive to do so. The analysis for F residents is completely symmetric, with a critical threshold $c_{P}^{F}=t r-\varepsilon$ and a fraction $\left(1-F_{F}(t r-\varepsilon)\right)$ of $F$ residents engaging in cross-border tax evasion. Thus, the outcomes in the pre-FATCA regime can be summarized as follows (as illustrated in Figure 1):

Proposition 1: Under the pre-FATCA regime:

a) All US residents with $c_{i}<c_{P}^{U S}=t r-\varepsilon$ will evade; thus, a fraction $F_{U S}(t r-\varepsilon)$ of US residents engage in cross-border tax evasion.

b) All F residents with $c_{i}<c_{P}^{F}=t r-\varepsilon$ will evade; thus, a fraction $F_{F}(t r-\varepsilon)$ of $\mathrm{F}$ residents engage in cross-border tax evasion.

c) The US government collects revenue $\operatorname{tr}\left(1-F_{U S}(\operatorname{tr}-\varepsilon)\right)$.

d) The F government collects revenue $\operatorname{tr}\left(1-F_{F}(t r-\varepsilon)\right)$.

Proof: Parts (a) and (b) follow straightforwardly from the argument in the text above. For part (c), recall that the US population is normalized to 1 , so that the amount of income reported to the US government is $r\left(1-F_{U S}(t r-\varepsilon)\right) * 1=r\left(1-F_{U S}(t r-\varepsilon)\right)$, and the applicable tax rate is $t$. Part (d) can be shown analogously for country F.

\subsection{2) The FATCA Regime}

Now, consider the introduction of a unilateral FATCA regime of the type described in Section 3. This involves the US government seeking to enlist FFIs in automatic reporting to the US of the income of US accountholders, using the threat of a punitive withholding tax to induce compliance with its demands. We focus only on FATCA-compliant equilibria, in which all FFIs comply with FATCA obligations and report information to the US (and where the withholding tax is thus not imposed in equilibrium). ${ }^{11}$ A FATCA-compliant equilibrium entails that FFIs expend

\footnotetext{
${ }^{11}$ A variety of non-FATCA-compliant equilibria are also possible. For instance, FFIs could respond to the introduction of FATCA by holding portfolios consisting only of non-US assets, thereby escaping the consequences of the punitive
} 
resources to develop an infrastructure for automatic information reporting of US residents' income to the US, and on determining whether each accountholder is a US tax resident (which is not straightforward, given the FATCA requirements to look through entities to the ultimate beneficial owner). Even if no US residents are discovered among current accountholders, the infrastructure of reporting to the US must be maintained and vigilance continually exercised against the possibility that US residents will seek to become accountholders. In other words, even if no US residents invest via FFIs in equilibrium, this outcome can only be supported by the out-ofequilibrium threat that a US accountholder's residence will be discovered and her information reported to the US. Moreover, this US reporting infrastructure must be maintained in addition to the system of automatic information reporting to the F government that is already in place.

Thus, the FATCA system imposes additional compliance costs on FFIs. Under the assumption of a competitive financial sector, this cost is borne by accountholders in the form of higher fees for investing via FFIs (in addition to the baseline fee of $\varphi$ ). We allow these additional fees to potentially differ for US and F accountholders. In particular, we assume the additional fee is $\varphi_{\text {FATCA }}^{U S}>0$ per accountholder for US accountholders and $\varphi_{F A T C A}^{F}>0$ per accountholder for $\mathrm{F}$ accountholders, where these fees are sufficiently small that $(1-t) r>\varphi+\varphi_{\text {FATCA }}^{i}$ where $i=F$, US. As the FATCA system assumed here is unilateral, these extra costs are asymmetric, in the sense that they apply to accountholders of FFIs, but not to accountholders of USFIs. It might be thought that since the FATCA system is aimed at US accountholders, the extra costs created by FATCA would be allocated by FFIs solely to US accountholders. Importantly, however, FFIs must verify the identity of all accountholders and must maintain a system enabling automatic reporting to the US even when there are no actual US accountholders. Thus, F accountholders also create costs for FFIs in the sense that the FFI must verify their non-US status to satisfy the requirements of FATCA. Crucially, to the extent that the FATCA regime imposes any costs at all on FFIs, these must be borne in any FATCA-compliant equilibrium by $\mathrm{F}$ residents, as there are no US accountholders of FFIs in such an equilibrium (as shown below). Thus, the assumption that $\varphi_{F A T C A}^{F}>0$ appears reasonable.

withholding tax. Alternatively, FFIs could hold US as well as non-US assets but incur the withholding tax rather than comply with FATCA obligations. This might be optimal for FFIs if the compliance costs of FATCA reporting to the US exceed the burden of the withholding tax. While these non-FATCA-compliant outcomes are theoretically possible, we focus here on FATCA-compliant equilibria, as these are more relevant for the central claims of the paper, and because (from the account in Section 3) it is clear that the intent of the FATCA system is to induce participation among FFIs. 
For a US resident, investing via either a USFI or an FFI now results in automatic income reporting to the US government (so that the probability of detection of evasion is 1). In effect, the US resident's choices are to invest via either a USFI or FFI, while complying in both cases. It is reasonable to assume that the translation cost $\gamma$ disappears for US investors in FFIs under FATCA - the FFI has to master US tax law, and so can provide US accountholders with their income as defined under US law at little or no additional cost. Thus, the payoff from investing via an FFI and complying is now:

$$
(1-t) r-\varphi-\varphi_{F A T C A}^{U S}-\varepsilon
$$

Thus, it is still a dominated strategy to attempt to comply with US tax law while investing via an FFI. US residents will therefore invest only via USFIs. Trivially, the US aim of eliminating crossborder tax evasion by US residents and increasing tax revenue is achieved in any FATCAcompliant equilibrium.

A resident of country F under a FATCA-compliant regime can invest via an FFI (which in effect implies compliance with F's tax law) and obtain a payoff of $(1-t) r-\varphi-\varphi_{\text {FATCA. If she }}^{F}$ invests instead via a USFI, she faces a lower fee (as the USFI does not incur $\varphi_{F A T C A}^{F}$ ). She can comply by incurring the tax translation cost $\gamma$ and obtain a payoff of $(1-t) r-\varphi-\varepsilon-\gamma \cdot{ }^{12}$ Alternatively, she can evade $\mathrm{F}$ taxes and obtain a payoff of $r-\varepsilon-\varphi-c_{i}$. If $\varphi_{F A T C A}^{F} \leq \gamma+\varepsilon$, then compliance through investing in an FFI is preferable to compliance through investment in a USFI. Thus, an F resident will evade iff:

i.e.

$$
\begin{aligned}
& r-\varphi-\varepsilon-c_{i}>(1-t) r-\varphi-\varphi_{F A T C A}^{F} \\
& c_{i}<t r-\varepsilon+\varphi_{F A T C A}^{F} \equiv c_{F A T C A}^{F}>c_{P}^{F}=t r-\varepsilon
\end{aligned}
$$

Thus, when $\varphi_{F A T C A}^{F} \leq \gamma+\varepsilon$, the critical threshold of evasion costs increases and hence evasion becomes more common among F residents as a result of the FATCA regime. Intuitively, the cost of behaving in conformity with F's laws increases because of the extra FATCA-related cost of investing via FFIs. On the other hand, the cost of evading via USFIs is unchanged. Thus, for those F residents whose $c_{i}$ falls between $t r-\varepsilon$ and $t r-\varepsilon+\varphi_{F A T C A}^{F}$, evasion now becomes optimal (as illustrated in Figure 2).

\footnotetext{
${ }^{12}$ Note that the translation cost $\gamma$ does not disappear for $\mathrm{F}$ residents investing via a USFI; under a unilateral FATCA regime, the USFI will not have any need to learn F tax law, and so the F investor in a USFI must still incur the translation cost to comply.
} 
If $\varphi_{\text {FATCA }}^{F}>\gamma+\varepsilon$, then compliance via USFIs is less costly than compliance via FFIs. F residents will thus invest only via USFIs. They will evade iff:

$$
r-\varphi-\varepsilon-c_{i}>(1-t) r-\varphi-\varepsilon-\gamma
$$

i.e.

$$
c_{i}<t r+\gamma \equiv c_{F A T C A}^{F}>c_{P}^{F}=t r-\varepsilon
$$

Again, the critical threshold of evasion costs increases and hence evasion becomes more common among $\mathrm{F}$ residents as a result of the FATCA regime. Here, the administrative costs $\varphi_{F A T C A}^{F}$ of FATCA are sufficiently large that they drive away all investment via FFIs (effectively eliminating the financial sector in F). For F residents, the cost of behaving in conformity with F's laws increases because of the tax law translation cost that they must now incur. On the other hand, the cost of evading via USFIs is unchanged. Thus, for those F residents whose $c_{i}$ falls between $t r-\varepsilon$ and $t r+\gamma$, evasion now becomes optimal. ${ }^{13}$

These outcomes can be summarized as follows:

Proposition 2: Under a unilateral FATCA regime:

a) No US residents engage in cross-border evasion, regardless of their value of $c_{i}$.

b) A larger fraction of $\mathrm{F}$ residents engage in cross-border evasion than under the pre-FATCA regime; specifically:

i. If $\varphi_{\text {FATCA }}^{F} \leq \gamma+\varepsilon$, then all $\mathrm{F}$ residents with $c_{i}<c_{F A T C A}^{F}=t r-\varepsilon+$ $\varphi_{F A T C A}^{F}$ will evade, where $c_{F A T C A}^{F}>c_{P}^{F}$; a fraction $F_{F}\left(t r-\varepsilon+\varphi_{F A T C A}^{F}\right)$ of $F$ residents engage in cross-border tax evasion.

ii. If $\varphi_{F A T C A}^{F}>\gamma+\varepsilon$, then all $\mathrm{F}$ residents with $c_{i}<c_{F A T C A}^{F}=t r+\gamma$ will evade, where $c_{F A T C A}^{F}>c_{P}^{F}$; a fraction $F_{F}(t r+\gamma)$ of $F$ residents engage in cross-border tax evasion.

c) The US government collects revenue $t r$.

d) The F government collects revenue $\operatorname{tr}\left(1-F_{F}\left(\operatorname{tr}-\varepsilon+\varphi_{F A T C A}^{F}\right)\right)$ under condition (i) and $\operatorname{tr}\left(1-F_{F}(t r+\gamma)\right)$ under condition (ii)

\footnotetext{
${ }^{13}$ Note that there is no requirement here that $\mathrm{F}$ residents are necessarily aware of the component of FI fees that are attributable to FATCA. In the model, F residents care about the total fee charged by an FI, e.g. $\varphi+\varphi_{F A T C A}^{F}$ in the case of an FFI under FATCA. Thus, their evasion behavior will respond to the increase in fees due to the increased compliance costs faced by FFIs under FATCA, even if they are unaware of the existence of the FATCA regime.
} 
Proof: Parts (a) and (b) follow straightforwardly from the argument in the text above. For part (c), recall that the US population is normalized to 1 , so that the amount of income reported to the US government is $r$ when there is no evasion, and the applicable tax rate is $t$. Part (d) holds for country F by a similar argument to that used for the corresponding result in Proposition 1.

The magnitude of the increase in evasion among $\mathrm{F}$ residents depends on the density function $f_{F}\left(c_{i}\right)$ around the neighborhood of $c_{F A T C A}^{F}$. It is possible that the increase in fees due to FATCA may be small, and that the responsiveness of evasion behavior to a small increase in fees is also small. However, it should also be remembered that there are a large number of non-US jurisdictions. Even if the effects are small in any single country, when aggregated over all non-US jurisdictions they may well rival the gains in compliance experienced by the US. In any event, this analysis points to a cost of a unilateral FATCA regime that should arguably be quantified and weighed against the benefits to the US; moreover, this cost can be measured in the same metric as the gains to the US, namely in the form of changes in tax compliance.

\subsection{3) Asymmetric Costs of Investing via USFIs}

The result that FATCA increases evasion among F residents seems to rely on their ability to redeploy investment to the US in a frictionless manner. It is possible, however, that there may exist asymmetric US-specific barriers to foreign residents investing via USFIs. ${ }^{14}$ Suppose that there exists a fixed cost $k_{U S}>0$ for F residents who invest via USFIs; this cost is assumed to be fixed in the sense that it is independent of the amount invested. This would raise the cost of evasion under both the pre-FATCA and FATCA regimes. In the pre-FATCA regime, the payoff from evasion would be $r-\varphi-\varepsilon-k_{U S}$. Evasion would be lower than in the baseline scenario, as only F residents with $c_{i}<t r-\varepsilon-k_{U S}$ would engage in evasion. Under FATCA, complying while investing via an FFI generates a payoff of $(1-t) r-\varphi-\varphi_{F A T C A}^{F}$. Complying while investing via a USFI generates a payoff of $(1-t) r-\varphi-\varepsilon-k_{U S}$. If $\varphi_{F A T C A}^{F} \leq \gamma+\varepsilon+k_{U S}$, then $\mathrm{F}$ residents with $c_{i}<t r-\varepsilon-k_{U S}+\varphi_{F A T C A}^{F}$ would engage in evasion, implying that evasion increases under FATCA. If $\varphi_{F A T C A}^{F}>\gamma+\varepsilon+k_{U S}$, then F residents will always invest via USFIs despite the additional cost $k_{U S}$, and $\mathrm{F}$ residents with $c_{i}<t r+\gamma$ will engage in evasion, implying again that evasion increases under FATCA. Thus, introducing an asymmetric US-specific cost of

\footnotetext{
${ }^{14}$ For instance, the USA PATRIOT Act of 2001 requires USFIs in certain circumstances to investigate and scrutinize non-US persons who open financial accounts with USFIs.
} 
cross-border investment does not fundamentally affect the basic result. Of course, if $k_{U S}$ were arbitrarily large, there would be no evasion in either the pre-FATCA or FATCA regimes and so no increase in evasion under the latter. Apart from this extreme case, however, evasion among $\mathrm{F}$ residents will increase under FATCA.

\subsection{4) Tax Deductibility of FIs' Fees}

Tax laws vary in their treatment of investment expenses. In some circumstances, these expenses may be deductible. It was noted earlier that the basic result is not significantly affected by the tax deductibility of FI fees. In essence, deductibility entails that a tax evader confers a benefit on her government by foregoing a deduction for investment expenses when evading taxes on investment income. ${ }^{15}$ This mitigates, but does not usually reverse, incentives for tax evasion. If $\varphi$ were deductible, then in the pre-FATCA regime the level of evasion would be somewhat lower, with US and F residents engaging in evasion iff $c_{i}<t(r-\varphi)-\varepsilon$. Under FATCA, an F resident can invest via an FFI and receive a payoff of $(1-t)\left(r-\varphi-\varphi_{F A T C A}^{F}\right)$. She can also invest via a USFI and comply, receiving a payoff of $(1-t)(r-\varphi)-\varepsilon-\gamma$. Investing via a USFI and evading would yield $r-\varphi-\varepsilon-c_{i}$. If $\varphi_{F A T C A}^{F} \leq \gamma+\varepsilon$, then an F resident would evade iff $c_{i}<$ $t(r-\varphi)-\varepsilon+(1-t) \varphi_{F A T C A}$. If $\varphi_{F A T C A}^{F}>\gamma+\varepsilon$, then an F resident would evade iff $c_{i}<t(r-$ $\varphi)+\gamma$. In either case, the threshold cost of evasion is higher and therefore the level of evasion is greater than in the pre-FATCA equilibrium. To that extent, the basic result is not affected by whether or not FI fees are tax deductible.

\subsection{5) A More General Formulation of the Costs of Evasion}

The basic framework above assumes a fixed cost of evasion $c_{i}$ for a given individual $i$. When investors' choices involve investing wholly through an FFI or through a USFI, this simplification is largely innocuous. However, in this subsection, we consider a more general formulation of the costs of evasion. In particular, suppose that individual $i$ is a resident of country F who has fixed wealth $W_{i}$. This individual chooses a fraction $\alpha$ of her wealth to invest via a USFI, with the remaining fraction $(1-\alpha)$ being invested via an FFI. Suppose that the fee charged by an FFI is $\varphi^{F}$ and the fee charged by a USFI is $\varphi^{U S}$; the tax rate is $t$. For simplicity, we ignore the

\footnotetext{
${ }^{15}$ Note that a similar point applies to losses (although losses are not directly relevant here because the diversified global portfolio is assumed to be riskless) - an evader confers a benefit upon her government by foregoing deductions for losses sustained within her hidden account.
} 
possibility of complying while investing via a USFI. ${ }^{16}$ Then, the amount of home country tax evaded is tra, where $r$ is the (pretax) income generated by the investment of wealth $W_{i}$ (as in the basic framework above, $r$ is invariant to whether investment is via and FFI or a USFI). We assume that the cost of evasion is an increasing, convex, twice continuously differentiable function $C_{i}(\operatorname{tr} \alpha)$. The assumption that the cost of evasion is a function of the amount of tax evaded is widely used in the tax evasion literature (e.g. Yitzhaki, 1974). One possible motivation is that the probability of detection increases with the amount evaded. Note also that we do not explicitly model the hedging of exchange rate risk, as this can be viewed as being included in $C_{i}(\operatorname{tr} \alpha)$, if for instance the cost of bearing (or hedging) exchange rate risk increases with $\alpha$.

Under these assumptions, the $\mathrm{F}$ resident's problem can be formulated as:

$$
\max _{\alpha} \alpha\left(r-\varphi^{U S}\right)+(1-\alpha)\left((1-t) r-\varphi^{F}\right)-C_{i}(\operatorname{tr} \alpha)
$$

The first-order condition can be expressed as:

$$
F\left(\alpha ; \varphi^{F}\right)=r-\varphi^{U S}-(1-t) r+\varphi^{F}-\operatorname{tr} C_{i}^{\prime}(\alpha)=0
$$

which implicitly defines the investor's optimal choice of $\alpha$ as a function of the underlying parameters, including $\varphi^{F}$. Suppose that the fee $\varphi^{F}$ charged by FFIs increases, for instance due to costs associated with the FATCA regime. Then, applying the Implicit Function Theorem, it follows that the fraction of an F resident's wealth that is invested abroad rises:

$$
\frac{d \alpha}{d \varphi^{F}}=-\frac{\frac{\partial F}{\partial \varphi^{F}}}{\frac{\partial F}{\partial \alpha}}=-\frac{1}{-\operatorname{tr} C_{i}^{\prime \prime}(\alpha)}>0
$$

(given that $C_{i}(\operatorname{tr} \alpha)$ is convex). Thus, when the costs associated with investing via FFIs increase, F residents will increase the extent to which they "hide" wealth abroad (and hence engage in increased tax evasion). This suggests that the paper's basic results are fairly robust to using a more general formulation of the costs of tax evasion.

\section{2) Adding a Haven Jurisdiction}

In this section, a third jurisdiction - a tax haven - is added to the model. The haven is assumed to have zero population, but to be the place of domicile of a competitive financial sector. In the pre-FATCA regime, these haven financial institutions (HFIs) are assumed to have a zero

\footnotetext{
${ }^{16}$ Note, however, that as long as it is more costly to comply when investing via a USFI than when investing via an FFI (for instance, because of the tax law translation costs discussed earlier), the equilibrium level of tax evasion by $\mathrm{F}$ residents will increase when $\varphi^{F}$ increases.
} 
cost of providing wealth management services. In the baseline model, the operating costs of FIs are normalized to zero; the costs and fees we assumed $(\varphi)$ were the result of compliance costs associated with information reporting to governments. HFIs face only these operating costs (normalized to zero), as the haven has no income tax system and so does not impose any information reporting requirements on HFIs. ${ }^{17}$

In the literature on tax havens (as surveyed, for instance, in Dharmapala (2008)), it is often assumed that havens charge a (positive) fee for their services. The assumption here that HFIs charge a zero fee may seem unrealistic. Recall, however, that this in part reflects the normalization of wealth management costs to zero for all FIs. Moreover, assuming that HFIs charge a strictly positive fee that is below $\varphi$ would not fundamentally affect the results. The assumption of a zero fee is consistent, for instance, with a scenario in which there are multiple identical HFIs that engage in Bertrand competition. A strictly positive fee would reflect a scenario in which the haven enjoys some degree of market power, for example due to a uniquely advantageous regulatory or governance environment.

Consider the expanded choices now available to a resident of country $\mathrm{F}$ in the pre-FATCA regime (the choices and outcomes for US residents are completely symmetrical). As before, she can invest via an FFI and comply (with payoff $(1-t) r-\varphi)$. She can invest via a USFI and either comply (with payoff $(1-t) r-\varphi-\varepsilon-\gamma$ ) or evade (with payoff $r-\varphi-\varepsilon-c_{i}$ ). Now, she can also invest via an HFI and either comply (with payoff $(1-t) r-\varepsilon-\gamma$ ) or evade (with payoff $\left.r-\varepsilon-c_{i}\right){ }^{18}$ Clearly, investing via an HFI dominates investing via a USFI, whether the individual pays country F's taxes or evades. Thus, the choice faced by an F resident is essentially between investing via an FFI and complying, investing via an HFI and complying, and investing via an HFI and evading. If $\gamma+\varepsilon \geq \varphi$, then an F resident will evade (via an HFI) iff:

$$
r-\varepsilon-c_{i}>(1-t) r-\varphi
$$

\footnotetext{
${ }^{17}$ Havens were traditionally notable for their bank secrecy laws that protected the identity of accountholders. More recently, however, many havens have signed TIEAs and agreed to participate in the regime of information exchange upon request. Thus, it is possible that some information reporting obligations may exist for HFIs, even if there is no domestic income tax system requiring the reporting of information. The costs associated with these obligations are ignored here. Note also that while the introduction of the haven reduces evasion costs for nonhaven residents (as described below), this does not rely on the existence of bank secrecy laws, or on any greater extent of illegal behavior by evaders than does cross-border evasion generally. Rather, the role of the haven is quite similar to that of any other foreign jurisdiction, apart from its lack of a domestic income tax and reporting regime.

${ }^{18}$ It is assumed that the cost $\varepsilon$ of hedging exchange rate risk is the same when investing via an HFI as when investing via a USFI.
} 
i.e.

$$
c_{i}<t r+\varphi-\varepsilon \equiv c_{H P}^{F}>c_{P}^{F}
$$

If $\gamma+\varepsilon<\varphi$, then an F resident will always invest via an HFI, and will evade iff:

$$
\begin{array}{ll} 
& r-\varepsilon-c_{i}>(1-t) r-\varepsilon-\gamma \\
\text { i.e. } & c_{i}<t r+\gamma \equiv c_{H P}^{F}>c_{P}^{F}
\end{array}
$$

In each case, the level of evasion is higher than in the absence of the haven.

The outcome under the pre-FATCA regime can be summarized as follows:

Proposition 3: Under the pre-FATCA regime, when there exists a haven jurisdiction:

a) All US residents with $c_{i}<c_{H P}^{U S}=t r+\min [\gamma, \varphi-\varepsilon]$ will evade via HFIs; thus, a fraction $F_{U S}(t r+\min [\gamma, \varphi-\varepsilon])$ of US residents engage in cross-border tax evasion.

b) All F residents with $c_{i}<c_{H P}^{F}=t r+\min [\gamma, \varphi-\varepsilon]$ will evade via HFIs; thus, a fraction $F_{F}(t r+\min [\gamma, \varphi])$ of $\mathrm{F}$ residents engage in cross-border tax evasion.

c) The US government collects revenue $\operatorname{tr}\left(1-F_{U S}(\operatorname{tr}+\min [\gamma, \varphi-\varepsilon])\right)$.

d) The F government collects revenue $\operatorname{tr}\left(1-F_{F}(\operatorname{tr}+\min [\gamma, \varphi-\varepsilon])\right)$.

Proof: Straightforward.

Now consider the choices open to an F resident when the FATCA regime is in place, noting that the FATCA obligations apply equally to FFIs and to HFIs. ${ }^{19}$ Thus, in any FATCA-compliant equilibrium, both FFIs and HFIs will impose the extra fee $\varphi_{F A T C A}^{F}$, thereby raising the costs to $\mathrm{F}$ residents of both complying via investment in FFIs and of either complying or evading via HFIs. The costs of either complying or evading via USFIs are unchanged. Whereas in the pre-FATCA regime, investment via an HFI always dominated investment via a USFI, this may not be the case under FATCA, depending on the relative magnitudes of $\varphi_{F A T C A}^{F}$ and the other parameters. Specifically, an F resident has the following choices and payoffs:

i) Invest via an FFI and comply: $(1-t) r-\varphi-\varphi_{F A T C A}^{F}$

ii) Invest via a USFI and comply: $(1-t) r-\varphi-\varepsilon-\gamma$

iii) Invest via a USFI and evade: $r-\varphi-\varepsilon-c_{i}$

\footnotetext{
${ }^{19}$ It seems reasonable to assume that FATCA obligations will apply to HFIs, as the US has concluded IGAs with a significant number of jurisdictions that are frequently classified as tax havens - see e.g. the classification of havens in Dharmapala and Hines (2009) and the list of countries with which IGAs exist, available at: https://www.treasury.gov/resource-center/tax-policy/treaties/Pages/FATCA.aspx
} 
iv) Invest via an HFI and comply: $(1-t) r-\varepsilon-\varphi_{F A T C A}^{F}-\gamma$

v) Invest via an HFI and evade: $r-\varepsilon-\varphi_{F A T C A}^{F}-c_{i}$

It can be shown that under our assumptions, the FATCA regime weakly increases evasion among F residents. Among US residents, the FATCA regime trivially eliminates cross-border evasion for the same reasons as discussed in the two-country setting. However, depending on the values of the parameters, US residents may comply either via USFIs or HFIs. These results can be summarized as follows:

Proposition 4: Under a unilateral FATCA regime, when there exists a haven jurisdiction:

a) No US residents evade, regardless of their value of $c_{i}$.

i. If $\varphi_{F A T C A}^{U S}+\gamma+\varepsilon<\varphi$, then all US residents invest via HFIs and comply

ii. If $\varphi_{F A T C A}^{U S}+\gamma+\varepsilon \geq \varphi$, then all US residents invest via USFIs and comply

b) A weakly larger fraction of $F$ residents engage in cross-border evasion than under the preFATCA regime; specifically:

i. If $\varphi_{F A T C A}^{F}<\varphi$ and $\gamma+\varepsilon<\varphi$, then all $\mathrm{F}$ residents with $c_{i}<c_{H F A T C A}^{F}=$ $t r+\gamma$ will evade, where $c_{H F A T C A}^{F}=c_{H P}^{F}$ (i.e. the level of evasion is identical to that in the pre-FATCA regime); a fraction $F_{F}(t r+\gamma)$ of $\mathrm{F}$ residents engage in cross-border tax evasion.

ii. If $\varphi_{F A T C A}^{F}<\varphi$ and $\gamma+\varepsilon \geq \varphi$, then all $\mathrm{F}$ residents with $c_{i}<c_{H F A T C A}^{F}=$ $\operatorname{tr}+\varphi-\varepsilon$ will evade, where $c_{H F A T C A}^{F}=c_{H P}^{F}$ (i.e. the level of evasion is identical to that in the pre-FATCA regime); a fraction $F_{F}(t r+\varphi-\varepsilon)$ of $\mathrm{F}$ residents engage in cross-border tax evasion.

iii. If $\varphi_{F A T C A}^{F} \geq \varphi$ and $\gamma+\varepsilon \geq \varphi$, then all $\mathrm{F}$ residents with $c_{i}<c_{H F A T C A}^{F}=$ $t r+\varphi_{F A T C A}^{F}$ will evade, where $c_{H F A T C A}^{F} \geq c_{H P}^{F}$ (i.e. the level of evasion is weakly higher than in the pre-FATCA regime); a fraction $F_{F}\left(t r+\varphi_{F A T C A}\right)$ of $\mathrm{F}$ residents engage in cross-border tax evasion.

iv. If $\varphi_{F A T C A}^{F} \geq \varphi+\varepsilon$ and $\gamma+\varepsilon<\varphi_{F A T C A}^{F}$, then all F residents with $c_{i}<$ $c_{\text {HFATCA }}^{F}=t r+\gamma$ will evade; ; a fraction $F_{F}(t r+\gamma)$ of $\mathrm{F}$ residents engage in cross-border tax evasion. If, furthermore, $\gamma+\varepsilon \geq \varphi$ then $c_{H P}^{F}=t r+$ $\varphi-\varepsilon$ and the level of evasion is higher than in the pre-FATCA regime If 
$\gamma+\varepsilon<\varphi$, then $c_{H P}^{F}=t r+\gamma$ and the level of evasion is unchanged relative to the pre-FATCA regime.

c) The US government collects revenue $t r$.

d) The F government collects weakly less revenue than in the pre-FATCA regime.

Proof: Parts (a) and (c) are straightforward. To show part (b):

i) If $\varphi_{\text {FATCA }}^{F}<\varphi$ and $\gamma+\varepsilon<\varphi$, F residents will always invest via HFIs (whether they plan to comply or evade). An F resident will thus evade iff:

$$
r-\varepsilon-\varphi_{F A T C A}^{F}-c_{i}>(1-t) r-\varepsilon-\varphi_{F A T C A}^{F}-\gamma
$$

i.e.

$$
c_{i}<t r+\gamma \equiv c_{H F A T C A}^{F}=c_{H P}^{F}
$$

as $c_{H P}^{F}=t r+\gamma$ from Equation (14) when $\gamma+\varepsilon<\varphi$.

ii) If $\varphi_{F A T C A}^{F}<\varphi$ and $\gamma+\varepsilon \geq \varphi$, then F residents will comply by investing via FFIs and evade by investing via HFIs. They will evade iff:

i.e.

$$
\begin{gathered}
r-\varepsilon-\varphi_{F A T C A}-c_{i}>(1-t) r-\varphi-\varphi_{F A T C A}^{F} \\
c_{i}<t r+\varphi-\varepsilon \equiv c_{H F A T C A}^{F}=c_{H P}^{F}
\end{gathered}
$$

as $c_{H P}^{F}=\operatorname{tr}+\varphi-\varepsilon$ from Equation (12) when $\gamma \geq \varphi$.

iii) If $\varphi_{F A T C A}^{F} \geq \varphi$ and $\gamma+\varepsilon \geq \varphi$, then F residents will comply by investing via FFIs and evade by investing via USFIs. They will evade iff:

i.e.

$$
\begin{aligned}
& r-\varepsilon-\varphi-c_{i}>(1-t) r-\varphi-\varphi_{F A T C A}^{F} \\
& c_{i}<t r+\varphi_{F A T C A}^{F}-\varepsilon \equiv c_{H F A T C A}^{F}>c_{H P}^{F}
\end{aligned}
$$

as $c_{H P}^{F}=t r+\varphi-\varepsilon$ from Equation (12) when $\gamma+\varepsilon \geq \varphi$.

iv) If $\varphi_{F A T C A}^{F} \geq \varphi+\varepsilon$ and $\gamma+\varepsilon<\varphi_{F A T C A}^{F}$, then $\mathrm{F}$ residents will always invest via USFIs (whether they plan to comply or evade). They will evade iff:

$$
r-\varepsilon-\varphi-c_{i}>(1-t) r-\varepsilon-\varphi-\gamma
$$

i.e.

$$
c_{i}<t r+\gamma \equiv c_{H F A T C A}^{F}
$$

To determine whether $c_{H F A T C A}^{F}>c_{H P}^{F}$, two distinct subcases must be considered:

a) If $\gamma+\varepsilon \geq \varphi$, then $c_{H P}^{F}=t r+\varphi-\varepsilon$ from Equation (12). Therefore, $c_{H F A T C A}^{F}<c_{H P}^{F}$.

b) If $\gamma+\varepsilon<\varphi$, then $c_{H P}^{F}=t r+\gamma$ from Equation (14), and $c_{H F A T C A}^{F}=c_{H P}^{F}$.

Part (d) follows straightforwardly from part (b). 
The introduction of a haven jurisdiction significantly complicates the analysis. However, it does not fundamentally overturn the result that a unilateral FATCA regime tends to erode tax compliance in country F, even as it reduces evasion among US residents. The intuition can be illustrated as follows. Consider the scenario in which F residents initially either comply via FFIs or evade via HFIs. An F resident who is initially compliant will face identical increases (of $\varphi_{F A T C A}^{F}$ ) in the cost of complying via an FFI and in evading via an HFI. Thus, evasion levels cannot fall. However, evasion may increase if it now becomes relatively less costly to evade via a USFI than via an HFI. If there are non-FATCA-related barriers to investment via USFIs (as discussed in Section 4.1.3), then the effect will be mitigated, but it will not be eliminated unless these barriers are prohibitive.

It is important to consider whether the unilateral FATCA regime imposed by the US may have spillover benefits for country F. For instance, it may seem that the higher cost of investing via havens may discourage tax evasion by F residents. This does not happen in the setup used here, because the cost of investing via an HFI and of investing domestically via an FFI both increase under the FATCA regime by $\varphi_{F A T C A}^{F}$. However, this type of spillover effect may be possible in other circumstances, for instance if $F$ residents have access to domestic investment opportunities that are not subject to the FATCA regime. In addition, the FATCA regime entails that tax havens engage in automatic information-sharing with the US. While information is not automatically shared with country F, it may still be difficult to achieve a partial abandonment of traditional tax haven practices. In particular, it is possible that havens' general reputation among cross-border evaders, including those from outside the US, may be undermined. In those circumstances, F residents may be less willing to invest in havens, thereby reducing evasion and increasing the revenues of country $\mathrm{F}$ (which could perhaps be modeled as an increase in the cost of evasion $c_{i}$ ).

\section{3) Discussion}

The model developed above provides a simple framework for understanding and analyzing cross-border tax evasion. In relation to the previous literature on tax evasion, it emphasizes two features of reality that have not been the focus of primary attention - cross-border investors' (heterogeneous) intrinsic motivation to comply with residence country tax law, and the impact of information reporting requirements on FIs' cost of financial intermediation. Under certain conditions, a unilateral FATCA regime - such as that enacted by the US in 2010 - causes increased 
cross-border tax evasion among residents of foreign countries. The basic mechanism is that the additional FATCA requirements that FFIs must undertake on behalf of US tax enforcement increase their costs. In essence, they must comply simultaneously with the information reporting requirements of their home government and those of the US. Assuming a competitive financial sector, this correspondingly raises the fees charged by FFIs to accountholders. Consequently, taxcompliant behavior - such as investing via the domestic financial sector - becomes more costly for F residents. In contrast, USFIs face only one set of information reporting requirements - that of the US - and so their costs are unchanged by the unilateral FATCA system. For F residents, the cost of evading via USFIs is unchanged, while the cost of tax-compliant behavior increases. This leads to a larger fraction of $\mathrm{F}$ residents engaging in cross-border evasion in equilibrium. The model is more complex when a haven jurisdiction is added, but the central intuition remains basically operative here as well.

The assumption of a competitive sector entails that increased FATCA-related costs of financial intermediation are borne by FFI accountholders. Their increased evasion reduces the tax revenues of the government of country F. Assuming instead an imperfectly competitive financial sector will mitigate but not in general eliminate the effect on evasion and revenue. If FFIs earn economic profits in equilibrium, then some fraction of these costs may be borne by the equityholders of FFIs or by financial sector workers. If these tend to be residents of country F, then the national welfare of country $F$ will be reduced because of the lower economic profits earned by FFIs. If FFIs share the burden of the incremental FATCA-related costs with accountholders, then the reduction in country F's tax revenues will be smaller than under the assumption of a competitive financial sector.

Thus, a unilateral FATCA regime entails potentially significant costs to country F, although the form in which these costs manifest themselves depend on the underlying economic setting. The US may also face some additional costs of monitoring participating FFIs' compliance with FATCA requirements (as noted by Gérard and Granelli (2013)). However, it is likely to derive essentially all of the benefits from a unilateral FATCA regime. Thus, one of the central concerns that has been expressed about FATCA is the mismatch of costs and benefits associated with the 
externalization of costs by the US - there is no reason to believe that the gains to the US from increased tax revenue would exceed the costs to other countries from this regime. ${ }^{20}$

The costs imposed by a unilateral FATCA regime on foreign countries (in addition to the legal and practical issues highlighted in Section 3) provide a rationale for why this regime has evolved towards greater reciprocity through IGAs. Thus, one interpretation of this paper's result is that it provides a reason for why a reciprocal FATCA-type regime - in which F residents have no means of increasing their evasion activity - may be preferred to a unilateral system. As discussed in Section 3, however, not all IGAs are reciprocal, and there are significant legal and political constraints on the extent to which reciprocity is likely to be realized in practice. Thus, the analysis in this paper arguably remains relevant, despite the spread of IGAs.

As a result of the travails of the unilateral FATCA regime, discussion has increasingly focused on the possibility of creating a multilateral FATCA-type system of global automatic reporting by all financial institutions to all of the world's governments. Blank and Mason (2014) suggest that FATCA, and in particular the IGAs to which it has given rise, may serve as the foundation of an incipient multilateral regime of automatic information reporting by all FIs to all of the world's governments. Such a multilateral regime would, in their view, supplant the preFATCA regime of information exchange upon request.

A multilateral system would eliminate the specific problem highlighted in this paper - F residents' evasion activity would not increase, as the F government would receive automatic reports about its residents' accounts from USFIs and HFIs. However, the more general issue of increased costs of financial intermediation would remain. Indeed, it would potentially be multiplied enormously because of the need for FIs to report to over 200 different governments and to keep track of the tax laws of each of these countries. For instance, if capital gains are subject to automatic reporting, then every financial institution in the world would have to learn whether or not a short sale "against the box" is a realization event in Ruritania. ${ }^{21}$ These costs could possibly

\footnotetext{
${ }^{20}$ If the costs to the rest of the world do indeed exceed the benefits to the US, the continued implementation of FATCA may seem to represent a failure of the Coase Theorem. However, it should be noted that there is no obvious mechanism by which FFIs or their governments could make side payments in a coordinated manner to the US in exchange for the repeal of FATCA. There is also no obvious commitment mechanism available for Congress to commit to not enacting similar legislation in the future.

${ }^{21}$ A short sale against the box is a transaction that involves the economic equivalent of the sale of stock, through the simultaneous holding of a long position and a short sale of the same number of shares. However, it does not trigger realization and hence capital gains taxation, in the absence of a specific anti-avoidance rule (such as exists in the US). It would not be possible for an FI to correctly report an accountholder's capital gains without knowledge of the tax law treatment of short sales against the box in the accountholder's residence country.
} 
be limited by the simplification and harmonization of tax law across countries, but this would require hitherto unprecedented levels of international tax cooperation.

Ultimately, whether the benefits of such a multilateral system would exceed its costs is an empirical question. In undertaking the relevant cost-benefit analysis, it should be borne in mind that the social gains from reducing tax evasion cannot simply be equated with the increase in revenues; rather, they reflect the welfare gains from the money being in the hands of the government rather than those of the taxpayer. These social gains will typically be positive as long as the marginal cost of public funds exceeds one, but may be substantially smaller in magnitude than the revenue gain (Slemrod and Yitzhaki, 1987). This paper does not undertake a comprehensive welfare analysis of this type, which would require a more complex framework. However, it highlights some neglected elements that should be featured in such an analysis.

\section{5) Conclusion}

The FATCA regime that was enacted by the US Congress in 2010 and that has recently begun to be implemented represents a fundamental transformation of cross-border tax enforcement. This paper presents a simple theoretical model of cross-border investment that analyzes the consequences of such a unilateral FATCA regime for tax compliance and tax revenues. The model emphasizes cross-border investors' (heterogeneous) intrinsic motivation to comply with residence country tax law, as well as the impact of information reporting requirements on the cost of providing financial services. In the baseline model - with two countries, the US and country F - the implementation of a unilateral FATCA regime by the US causes increased crossborder tax evasion among residents of F. By raising the costs to FFIs of providing financial services, a unilateral FATCA regime makes tax compliance for F residents more costly, inducing a larger fraction of the population of $F$ to engage in cross-border evasion. This result is robust to various relevant extensions, although it is difficult to determine its magnitude.

Historically, mandated information reporting has proven to be a powerful tool of tax enforcement. However, information reporting imposes costs on financial institutions that raise the costs of financial services. In an open-economy setting, this may drive taxpayers to hold foreign accounts, thereby increasing opportunities for evasion. The paper's main result is thus a specific illustration of more general lessons relating to the complex and sometimes unintended interactions among information reporting, intrinsic motivation, and tax evasion. 


\section{References}

Michael G. Allingham and Agnar Sandmo (1972), "Income Tax Evasion: A Theoretical Analysis” Journal of Public Economics, 1 (3-4), 323-338.

Andreoni, J., Erard, B., \& Feinstein, J. (1998) “Tax compliance” Journal of Economic Literature, 36(2), 818-860.

Philippe Bacchetta and Maria Paz Espinosa (1995), “Information Sharing and Tax Competition among Governments” Journal of International Economics, 39 (1), 103-121.

Blank, J. D. and R. Mason (2014) “Exporting FATCA” New York University Law and Economics Research Paper No. 14-05.

Christians, A. (2013) "What you give and what you get: Reciprocity under a Model 1 Intergovernmental Agreement on FATCA” Working paper, available at:

http://papers.ssrn.com/sol3/papers.cfm?abstract_id=2292645

Desai, M. A., \& Dharmapala, D. (2011) “Dividend taxes and international portfolio choice” Review of Economics and Statistics, 93(1), 266-284.

Dharmapala, D. (2008) “What problems and opportunities are created by tax havens?” Oxford Review of Economic Policy, 24(4), 661-679.

Dhammika Dharmapala and James R. Hines, Jr. (2009), "Which Countries become Tax Havens?” Journal of Public Economics, 93 (9), 1058-1068.

Dizdarevic, M. A. (2011) “The FATCA Provisions of the Hire Act: Boldly Going Where No Withholding Tax Has Gone Before” Fordham Law Review, 79, 2967-2994.

Dwenger, N., Kleven, H., Rasul, I., \& Rincke, J. (2015) “Extrinsic and intrinsic motivations for tax compliance: evidence from a field experiment in Germany” American Economic Journal: Economic Policy, forthcoming.

Eccleston, R. and Gray, F., (2014) "Foreign accounts tax compliance act and American leadership in the campaign against international tax evasion: revolution or false dawn?” Global Policy, 5(3), 321-333.

Gérard, M., \& Granelli, L. (2013) "From the EU Savings Directive to the US FATCA, Taxing Cross Border Savings Income” Université Catholique de Louvain, Institut de Recherches Economiques et Sociales (IRES) Working Paper No. 2013007.

Grinberg, I. (2012) “The Battle over Taxing Offshore Accounts” UCLA Law Review, 60, 304383. 
Harvey, J. R. (2012) “Offshore Accounts: Insider's Summary of FATCA and Its Potential Future” Villanova Law Review, 57, 471-498.

Johannesen, N. (2012) “Taxing hidden wealth - lessons for policy making” EUI Working paper RSCAS 2012/25.

Keen, M., \& Ligthart, J. E. (2006) "Information sharing and international taxation: a primer” International Tax and Public Finance, 13(1), 81-110.

Henrik Jacobsen Kleven, Martin B. Knudsen, Claus Thustrup Kreiner, Søren Pedersen and Emmanuel Saez (2011), "Unwilling or Unable to Cheat? Evidence from a Tax Audit Experiment in Denmark”, Econometrica 79 (3), 651-692.

Luttmer, E. F., \& Singhal, M. (2014) “Tax Morale” Journal of Economic Perspectives, 28(4), 149-68.

Morse, S. C. (2012) “Ask for Help, Uncle Sam: The Future of Global Tax Reporting” Villanova Law Review, 57, 529-550.

Joel Slemrod and Shlomo Yitzhaki (1987), “The Optimal Size of a Tax Collection Agency”, Scandinavian Journal of Economics, 89 (2), 183-192.

T. N. Srinivasan (1973), “Tax Evasion: A Model”, Journal of Public Economics, 2 (4), 339-346.

Shlomo Yitzhaki (1974), “Income Tax Evasion: A Theoretical Analysis”, Journal of Public Economics, 3 (2), 201-202.

Zucman, G. (2014) “Taxing across Borders: Tracking Personal Wealth and Corporate Profits” Journal of Economic Perspectives, 28(4), 121-148. 
Figure 1: The Pre-FATCA Equilibrium (Country F)

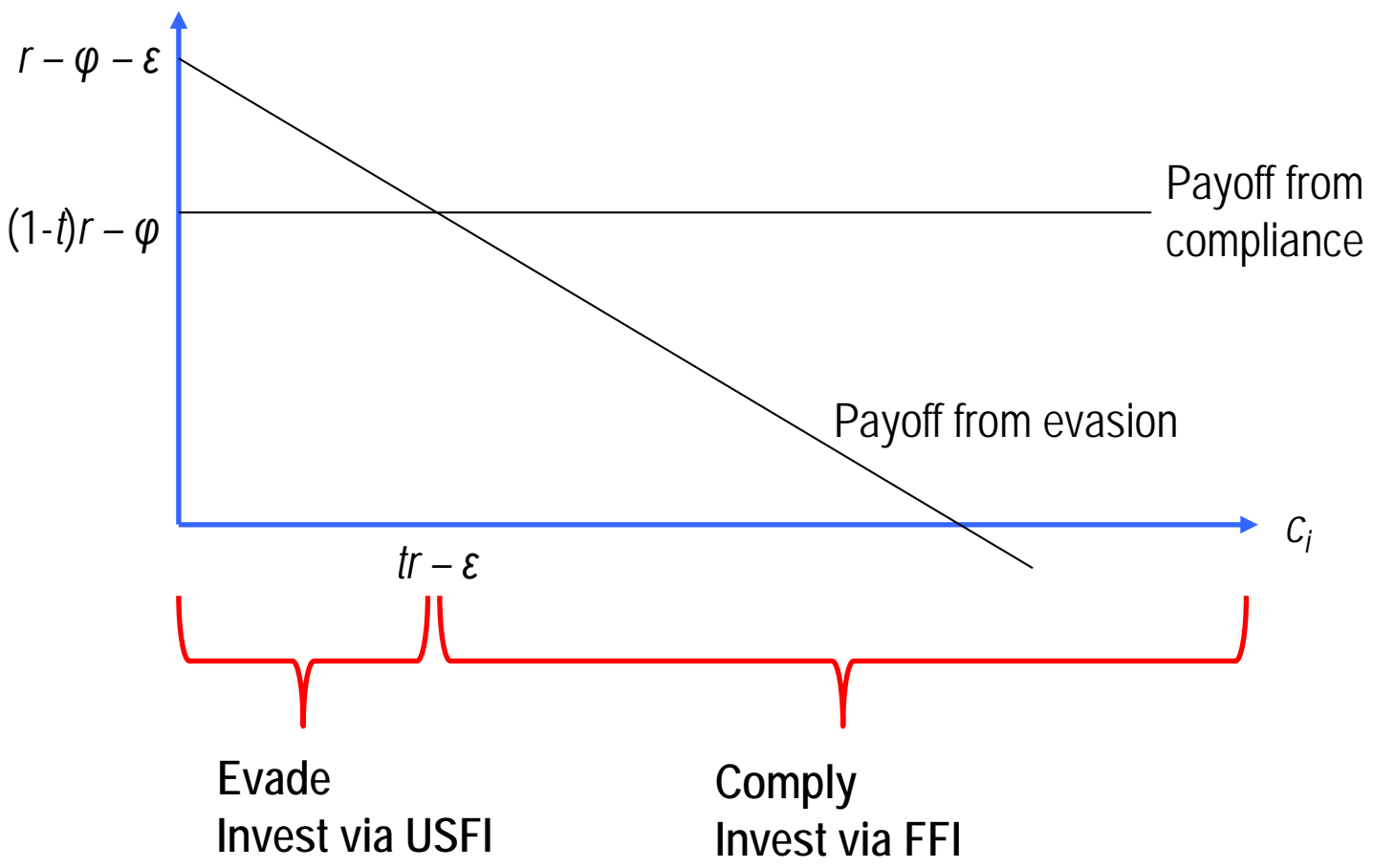

Figure 2: The FATCA Equilibrium (Country F, assuming $\varphi_{F A T C A}^{F}<\gamma$ )

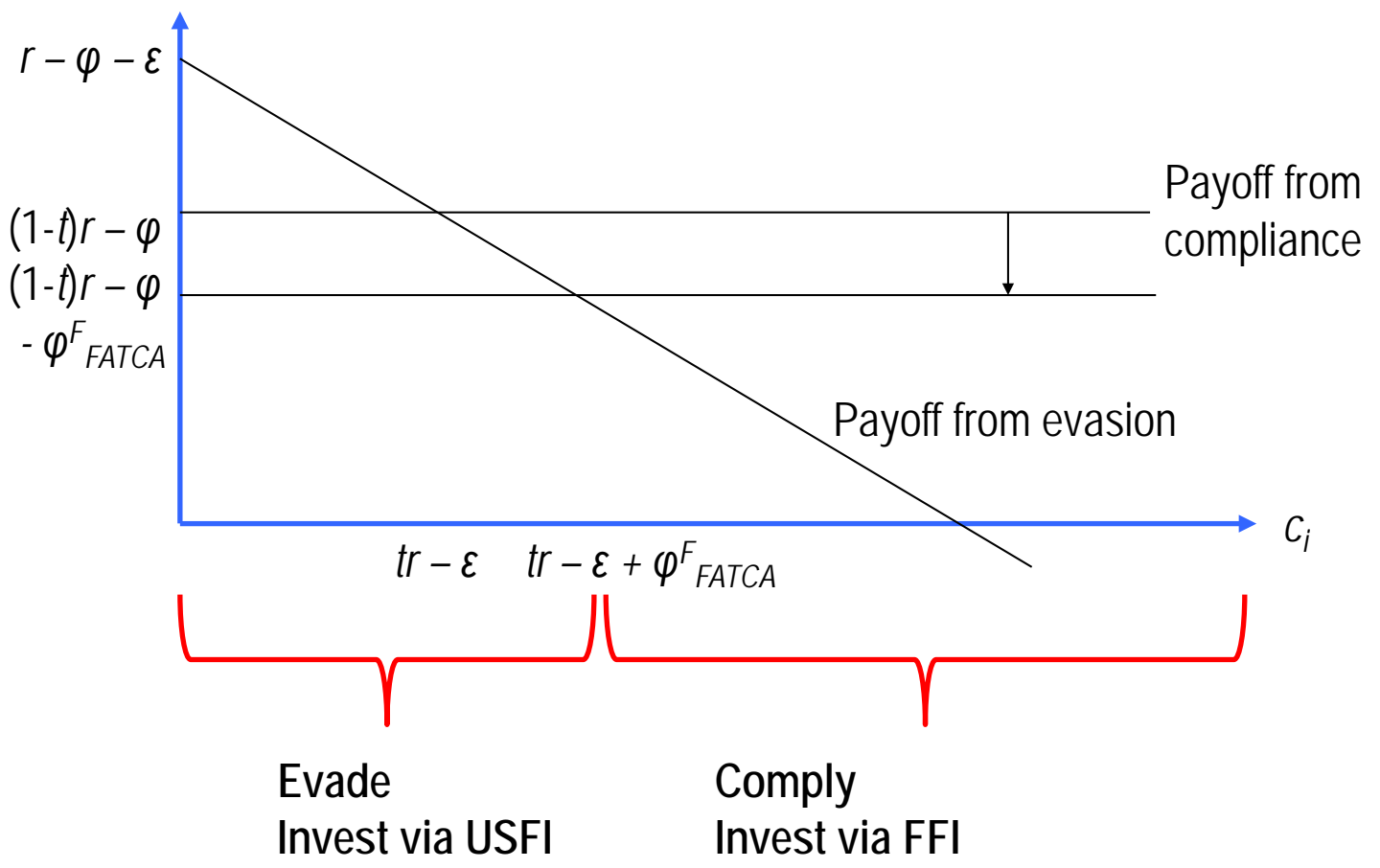

